\title{
Investigação colaborativa e o processo de formação de redes de conhecimento
}

\author{
Solange Martins Oliveira Magalhães ${ }^{1}$ \\ Tiago Zanquêta de Souza ${ }^{2}$ \\ Susana Beatriz Argüello ${ }^{3}$
}

\begin{abstract}
RESUMO
$\mathrm{O}$ artigo tem por tema as experiências da investigação colaborativa na consolidação de redes de conhecimento, a partir da experiência da Redecentro - Rede de Pesquisadores sobre o Professor da Região CentroOeste, Brasil. Tem por objetivo contribuir com o debate acerca da presença de obstáculos epistemológicos que interferem nos processos de metacognição e vigilância epistemológica, comprometendo a qualidade social da produção do conhecimento. Inspirados na sistematização de experiências, estruturamos o artigo em torno de duas categorias centrais: 1. a investigação colaborativa e em rede, especialmente no contexto da Redecentro; e 2. o processo formativo de pesquisadores(as), com foco em princípios orientadores da metacognição e da vigilância epistemológica. Concluímos que a convivência coletiva e colaborativa consolida um espaço aberto e sensível à socialização de dúvidas e experiências, além de influenciar o sentido colaborativo-crítico na realização das investigações com mais segurança e autonomia, fortalecendo processos emancipatórios e humanizadores, para além das redes de pesquisa.
\end{abstract}

PALAVRAS-CHAVE: Investigação Colaborativa. Redes de Conhecimento. Metacognição. Vigilância Epistemológica.

\footnotetext{
1 Doutora em Educação. Professora do curso de Pedagogia e Pós-Graduação em Educação da Faculdade de Educação, Universidade Federal de Goiás (UFG). Goiânia. Goiás, Brasil. Orcid: https://orcid.org/0000-0003-1187112X.E-mail: solufg@hotmail.com.

${ }^{2}$ Doutor em Educação. Professor do Programa de Pós-Graduação em Educação (mestrado e doutorado) e do Programa de Mestrado Profissional em Educação: formação docente para a Educação Básica, ambos da Universidade de Uberaba (Uniube). Uberaba. Minas Gerais, Brasil. Orcid: https://orcid.org/0000-0002-2690-4177.E-mail: tiago.zanqueta@uniube.br.

${ }^{3}$ Magister en Políticas Sociales (Universidad Nacional de Salta, Argentina). Doctoranda en Ciencias Sociales (UNJu, Argentina). Profesora Titular de las cátedras de Universidad y Formación Docente y de Planeamiento de la Educación, Carrera de Ciencias de la Educación, Facultad de Humanidades y Ciencias Sociales, Universidad Nacional de Jujuy, Argentina. Orcid: https://orcid.org/0000-0003-2356-2391. E-mail: montear@arnet.com.
} 
Collaborative research and the process of forming knowledge networks

\begin{abstract}
The article is based on the experiences of collaborative research in the consolidation of knowledge networks, based on the experience of Redecentro - Rede de Pesquisadores sobre o Professor da Região Centro-Oeste, Brazil. It aims to contribute to the debate about the presence of epistemological obstacles that interfere in the processes of metacognition and epistemological surveillance, compromising the social quality of knowledge production. Inspired by the systematization of experiences, we structured the article around two central categories: 1. collaborative and networked research, especially in the context of Redecentro; and 2. the training process of researchers, with a focus on guiding principles of metacognition and epistemological surveillance. We conclude that the collective and collaborative coexistence consolidates an open and sensitive space to the socialization of doubts and experiences, in addition to influencing the collaborative-critical sense in carrying out investigations with more security and autonomy, strengthening emancipatory and humanizing processes, in addition to the research networks.
\end{abstract}

KEYWORDS: Collaborative Research. Knowledge Networks. Metacognition. Epistemological surveillance.

Investigación colaborativa y proceso de formación de redes de conocimiento

\title{
RESUMEN
}

El artículo tiene como tema las experiencias de investigación colaborativa en la consolidación de redes de conocimiento, a partir de la experiencia de Redecentro - Red de Investigadores del Docente de la Región Medio Oeste, Brasil. Tiene como objetivo contribuir al debate sobre la presencia de obstáculos epistemológicos que interfieren en los procesos de metacognición y vigilancia epistemológica, comprometiendo la calidad social de la producción de conocimiento. Inspirándonos en la sistematización de experiencias, estructuramos el artículo en torno a dos categorías centrales: 1. Investigación colaborativa $\mathrm{y}$ en red, especialmente en el contexto de Redecentro; y 2. el proceso de formación 
de investigadores, con un enfoque en los principios rectores de la metacognición y la vigilancia epistemológica. Concluimos que la convivencia colectiva y colaborativa consolida un espacio abierto y sensible a la socialización de dudas y experiencias, además de incidir en el sentido colaborativo-crítico en realizar investigaciones con más seguridad y autonomía, fortaleciendo procesos emancipadores y humanizadores, además de las redes de investigación.

PALABRAS CLAVE: Investigación colaborativa. Redes de conocimiento. Metacognición. Vigilancia epistemológica.

$$
* * *
$$

A trajetória de fazer pesquisa no coletivo é exigente em relação ao indispensável diálogo, como método fundamental de trabalho. O diálogo implica também no desenvolvimento da tolerância para ouvir e respeitar os interlocutores, aceitar e ou confrontar posicionamentos diversos, desenvolver pensamento crítico e humildade intelectual, entre outros aspectos (...) que se apresentam importantes na trama do fazer colaborativo Ana Maria Saul (2016, p. 15).

\section{Introdução}

A epígrafe nos ampara quanto à importância da interlocução coletiva na trajetória da pesquisa, sobretudo ao apontá-la como fundamental às transformações das nossas próprias formas de ser, sentir, estar, perceber e pensar no mundo e com o mundo. Também nos ajuda a perceber que as mudanças passam pela resignificação do agir na pesquisa, como o resultado de processos metacognitivos. Nos termos de Vygotsky (1991), as mudanças ancoram-se em mediações, e a partir delas trona-se possível a construção de ferramentas psicológicas superiores, que influenciarão nas tomadas de decisões dos sujeitos, inclusive daquelas voltadas ao desenvolvimento proativo, crítico, emancipador e humanizador.

A mesma discussão também pode ser aportada no debate estabelecido por Pérez, Gómez Galindo e González Galli (2021), a partir de nossa tradução e 
interpretação, uma vez que auxiliam na conjunção das interlocuções coletivas (ou mediações) aos processos metacognitivos, o que acaba por consolidar uma conjunção responsável pela superação de um pensamento linear, baseado, por exemplo, no senso comum (ZANOLLA, 2012).

Por meio do que colocam os autores supracitados, ainda se reforça que o pensamento linear é muito presente entre pesquisadores(as) - iniciantes, alunos(as) de graduação, de pós-graduação, bolsistas etc., amalgamando dificuldades no apreender de determinados referenciais teóricos ou conceituais, fazendo com que os sujeitos persistam na natureza e no funcionamento de concepções errôneas, e, em muitos casos, bloqueiam progressos na aprendizagem, influenciando até mesmo sua própria produção do conhecimento.

Podemos inferir, a partir de nossa experiência como pesquisadoras e pesquisador na Redecentro (Rede de Pesquisadores sobre o professor na região Centro-Oeste/Brasil), que a presença do pensamento linear é uma dificuldade recidiva e bem comum entre nossos(as) estudantes. Digamos que eles(as) não aprendem (talvez em em muitos casos nem são ensinados) os modelos mais básicos e conceituais, conforme as regras dos paradigmas científicos, o que gradativamente vai comprometendo a resolução de problemas básicos, no campo da formação no nível da pós-graduação. Por esse motivo, Pérez, Gómez Galindo e González Galli (2021, p. 28) enfatizam que várias linhas de pesquisa buscam investigar o que eles definem como sendo um “obstáculo epistemológico". Para eles esse tipo de obstáculo influi diretamente nos modos gerais de pensamento dos(as) pesquisadores(as), e, na maioria das vezes, torna-se um "entrave nas formas de raciocínio exigido no aprendizado de novos modelos/paradigmas ou conteúdos científicos”. Os autores definem teoricamente o termo obstáculo epistemológico, ao indicarem suas principais características:

1. Transversalidade - têm um certo grau de generalidade em relação aos fenômenos que permitem explicar (...) fundamentam as concepções de diferentes domínios do conhecimento. 2. Funcionalidade - têm uma função explicativa para o assunto (...) geram uma rede entre conceitos com os 
quais os sujeitos descrevem, explicam e predizem o mundo em que vivem. 3. Conflito - dificultam a aprendizagem e/ou aceitação do modelo científico a ser ensinado, na medida em que explicam o mesmo fenômeno que explica o modelo científico de referencia (PÉREZ, GÓMEZ GALINDO; GONZÁLEZ GALLI, 2021, p. 29. Tradução nossa).

A partir do conceito exposto, a presença do obstáculo epistemológico gera certo grau de generalidade em relação aos fenômenos, pois sustenta uma função explicativa baseada no senso comum para todos os fenômenos. Além disso, pelo esforço na manutençao de determinadas explicações, acaba por dificultar novas aprendizagens e/ou a aceitação de aspectos relacionados ao modelo científico adotado na investigação colaborativa. Sabemos que muitos pesquisadores relutam mudar suas "certezas" e tradições teóricas ou, às vezes, buscam sustentar certos modismos, em termos teóricos, negando os princípios teórico-metodológicos que lhes dariam maior capacidade de leitura da realidade, como a que Freire $(1971)^{4}$ alertava.

Souza (2017), ao se orientar em Freire (2011a), reconhece a necessidade de utilizar-se da realidade concreta como ponto de partida, como via de acesso para construir a consciência crítica, de modo a oportunizar a problematização da realidade. É preciso considerar, por isso, que o conhecimento se constrói a partir da realidade concreta. Para Freire (2011b), o conhecimento é um processo de construção coletiva mediada dialogicamente, numa interação dialética entre experiência da vida prática com a sistematização rigorosa e crítica.

Nesse sentido, o obstáculo epistemológico é responsável por regulações do pensamento, acarretando distorções da realidade para que ela se encaixe em conceitos cristalizados, a fim de manter a doxa, o que ocorre quase de forma automática, simplificada, inviabilizando questionamentos críticos nas interpretações da e sobre a realidade.

\footnotetext{
4 "Para muitos de nós, a realidade concreta de uma certa área se reduz a cum conjunto de dados materiais ou de fatos cuja existência ou não, de nosso ponto de vista, importa constatar. Para mim, a realidade concreta é algo mais que fatos ou dados tomados mais ou menos em si mesmos. Ela é todos esses fatos e todos esses dados e mais a percepção que deles esteja tendo a população neles envolvida” (FREIRE, 1971, p.35).
} 
Convivemos com o mesmo problema e, no nosso entendimento, ele exige constantes posturas formativas para que os(as) pesquisadores(as) consigam se filiar, com consistência teórica e metodológica, às redes de conhecimento. Além disso, devemos ponderar sobre a terceira tese de Feuerbach que já nos alertou sobre a necessidade de se educar o próprio pesquisador, pois como trabalhador intelectual, está envolto com uma atividade humana (pesquisa) que apreende o mundo pela atividade subjetiva que transforma a si mesmo. Portanto, a pesquisa gera mudanças no(a) pesquisador(a), mas como as condições histórico-sociais sempre se inter-relacionam, os fenômenos só poderão ser compreendidos, por meio de uma crítica radical que consiga romper com o aparente, desde que essa esteja conectada a uma práxis revolucionária (MARX, [1846] 1986).

A investigação colaborativa alude a práxis, exige sempre uma interlocução referendada no diálogo, na dialogicidade, no respeito, numa postura formativa que tem o propósito de mudar o pensamento dos sujeitos para mudar a forma como atua na pesquisa. Por certo, existem possibilidades de se superar os obstáculos epistemológicos e, assim, ampliar-se-á a capacidade de manter a vigilância epistemológica (SOUZA; MAGALHÃES, 2019; MAGALHÃES; SOUZA, 2018; 2019). Novos processos metacognitivos continuarão ajudando, como anunciam Gómez Galindo e González Galli (2021), na superação dos obstáculos epistemológicos, ao cabo, altera-se a produção do conhecimento, fortalecendo o campo da pesquisa educacional.

O entendimento descrito perpassa a experiência da investigação colaborativa da Redecentro - Rede de Pesquisadores sobre Professores da Região Centro-Oeste/Brasil, como já anunciado anteriormente. A ideia reforça a importância de manter o foco no processo de formação de nossos(as) pesquisadores(as) para que consigam superar obstáculos epistemológicos que interferem e regulam, não só o próprio pensamento, mas a lógica e a qualidade da produção acadêmica. 
A metodologia que ancora esta produção textual também pode ser aproximada da Sistematização de Experiências, de Holliday (2006). Ela potencializa uma compreensão aprofundada das experiências que vivemos e realizamos, no âmbito da Redecentro, cuja finalidade, em última instância, é suscitar a melhoria de nossas próprias práticas, no exercício constante da reflexão crítico-teórica acerca dos conhecimentos oriundos a partir das práticas sociais concretas vivenciadas.

Segundo Holliday (2006, p.29) a sistematização de experiências "é sempre um meio em função de determinados objetivos que a orientam e lhe dão sentido. Quer dizer, em função de uma utilidade concreta que vamos lhe dar, em relação com as experiências que estamos realizando". Nesse sentido, sistematizamos nossas experiências em torno de duas categorias centrais: 1. a investigação colaborativa e em rede, especialmente no contexto da Redecentro; e 2. o processo formativo de pesquisadores(as), com foco em princípios orientadores da metacognição e da vigilância epistemológica, tão caros à pesquisa colaborativa e em rede.

Com base nisso, objetivamos, com este artigo, contribuir com o debate acerca da presença de obstáculos epistemológicos que interferem nos processos de metacognição e vigilância epistemológica, no nosso entendimento, acabam comprometendo a qualidade social da produção do conhecimento e, para isso, apresentamos teoricamente alguns princípios formativos estruturantes - teórico, epistemológico, gnosiológico, ontológico, metodológico, político e ideológico, e relacional, por sua influencia nos processos de metacognição, por esse inflir na consolidação de um novo pensamento sobre a realidade. Por certo, os princípios indicados acabm por ajudar a consolidar uma mudança conceitual no pensar dos pesquisadores sobre a pesquisa, por consolidar uma ormação teórica e filosófica dos mesmos.. Por certo, ao ajudar a constituir um novo pensar sobre a pesquisa - te'rocio e filosófico, influencia-se diretamente nas possibilidades de "vigilância epistemológica", logo, na qualidade social das pesquisas (SOUZA; MAGALHÃES, 2017). 


\section{A investigação colaborativa a partir da Redecentro - Rede de Pesquisadores sobre professores da Região Centro-Oeste/Brasil}

Franco e Morosini (2001, p. 36) afirmam que as "redes normalmente são construídas para manter unidas as pessoas com níveis semelhantes de habilidades e experiência que, somando os seus esforços, possam alcançar resultados melhores do que se trabalhassem cada uma por si só". Somandose a esta questão, concordamos com Morosini (2003, p. 221) que ainda afirma que "as redes são uma das vias mais propícias para o estabelecimento de um espaço multicultural".

Nos termos dos autores supracitados, afirmamos que a investigação colaborativa desenvolvida pela Redecentro, iniciou composta pelas seguintes instituições: Universidade Federal de Goiás (UFG/Brasil), Universidade de Brasília (UNB/Brasil), Universidade Federal de Uberlândia (UFU/Brasil), Universidade de Uberaba (UNIUBE/Brasil), Universidade Federal do Tocantins (UFT/Brasil), Universidade Federal de Goiás/Catalão (UFCAT/Brasil). Com a consolidação do grupo, inclusive institucionalmente, e jé se vão 15 anos de trabalho conjunto, buscamos expandir associando pesquisadores(as) internacionais. Nosso objetivo foi ampliar estudos e retratar a realidade dos docentes e a realidade educacional na América Latina, como propõe também Severino (2019).

No processo foram incorporados(as) pesquisadores(as) internacionais filiados a Faculdade de Ciências Humanas e Sociais (UNJu/San Salvador de Jujuy/Argentina) e a Faculdade de Ciências Humanas (Unicen/Tandil/Argentina). O novo grupo que se somou à Redecentro, trouxe outras e novas experiências e reflexões, ampliando objeto de estudos e focos de análises. Atualmente, seguimos juntos reinventando metodologias de trabalho coletivo, por meio do uso das mídias digitais, como por exemplo, para realização de estudos e discusões sobre os encaminhamentos da pesquisa, análise dos dados e publicização dos resultados. 
Com as novas pacerias, seguimos na consolidação do objetivo comum da Redecentro, que é o de criar outras formas de cooperação pessoal e institucional que favoreçam a investigação colaborativa na e para a melhoria daeducação, enquanto meio e fim das atividades dos professores.

No nosso caso, a união entre as equipes de pesquisa foi formalizada por intermédio de um termo específico de parceria - Termo de Parceria Interinstitucional. O termo estabelece formas de colaboração, o que é, não só natural, como legítimo. Afinal, sabemos que o simples fato de diversas pessoas trabalharem em conjunto não significa que se esteja, necessariamente, implementando uma situação de colaboração. Por isto, o termo de parceria estipula direitos e deveres que precisam ser compreendidos e respeitados, não como um fim em si mesmo, mas como um meio para atingir objetivos comuns.

No termo, as relações de trabalho são definidas numa relação hierárquica, eleita e rotativa entre as instituições, mas numa base de igualdade de modo a haver ajuda mútua para atingir metas que beneficiem todo o grupo de pesquisa. $\mathrm{O}$ documento, que foi assinado pelas reitorias de cada instituição, define a organização das equipes de pesquisa, princípios orientadores, objetivos e metodologias comuns à todos os integrantes da Redecentro. Uma vez acordado, o trabalho que passou a ser empreendido pelo coletivo, pautou-se em uma base comum que tem a ver com os objetivos da referida Rede.

Instituiu-se assim, um projeto coletivo, interinstitucional, e agora internacional, que tem um objetivo comum geral partilhado por todos(as). Nesse sentido, a coordenação consiste parte importante da investigação colaborativa e em rede, que cuida da gestão das atividades das pessoas e dos recursos para atingir um fim. Segundo Alves (2007) ela fundamenta-se em três variáveis: a tarefa (atividade colaborativa desenvolvida pelo trabalho em conjunto e pela ajuda entre todos os membros), a constituição e composição do grupo (fatores como o tamanho, homogeneidade ou heterogeneidade em relação à idade, a experiência, aos conhecimentos técnicos, a formação, etc.) e 
a motivação (promovida através dos meios que privilegiam a socialização, paticularmente as redes de conhecimento). No conjunto, esses aspectos precisam ser geridos e implementados por um líder democrático.

A Redecentro conta hoje com aproximadamente 15 professores(as) pesquisadores(as) sêniores, 20 pesquisadores(as) colaboradores(as) (alunos e ex-alunos de graduação, de pós-graduação, professores(as) da rede de ensino, bolsistas de iniciação científica, monitores e bolsistas Prolicen), consolidando um grupo amplo, heterogêneo, sujeito a constantes mudanças que ocorrem, quer seja em função da finalização dos cursos de mestrado e doutorado, ou pelo término das bolsas de iniciação científica. Por isso, temos a constante necessidade de novas estratégias para que o grupo possa superar, de forma criativa e construtiva, as demandas para sua permanência e reciclagem, inclusive teórica.

As estratégias que compõem nossa metodologia do trabalho, a qual envolve grupos de estudo, discussão e debates, reuniões técnicas para aprimoramento e reformulações de metodologias, construção e revisão de instrumentos de análise, apresentação e publicação dos resultados, (re)avaliação constante do processo, articula sempre o objetivo de dar maior clareza de propósitos e distanciamento do sentido instrumentalista e mecanicista de um fazer pesquisa acadêmica. No processo, temos buscado tornar a jornada menos errática, mais consciente de que a tarefa do grupo é primeiramente formativa e constitutiva de nós mesmos e de outros(as) pesquisadores(as) que a nós se associam.

Do ponto de vista das bases teóricas, epistemológicas e metodológicas, a Redecentro tem se pautado nos pressupostos do materialismo histórico-dialético, da fenomenologia, optando também por uma abordagem qualitativa de pesquisa, como possibilidade de problematizar seus objetos de estudo em sua complexidade. Quanto ao sentido crítico, inerente às vertentes teóricas com as quais trabalhamos, há sempre a necessidade de formação específica, além do fortalecimento do posicionamento político e ideológico contra hegemônico, calcado nos 
pressupostos teórico-epistemológicos de autores(as), o que também inclui os latino-americanos(as).

É preciso salientar que, por meio de nossa experiência, as potencialidades da investigação colaborativa nos têm apoiado na profissão, e nos parece que também temos conseguido investir numa dupla responsabilidade indissociável: criar as melhores condições de trabalho e ampliar a capacidade de desenvolver ações para promover a nós mesmos e aos colegas (apoio no desenvolvimento profissional).

No conjunto, vários aspectos se destacam como benéficos ao trabalho da investigação colaborativa. Ao longo de nossos anos de trabalho coletivo, os aspectos positivos tornam-se os mais importantes e marcantes, inclusive definindo o movimento de pesquisa como práxis (SOUZA; MAGALHÃES, 2017).

A partir dessa construção que é histórica e convive com vários determinantes, no recorte desse artigo damos ênfase a importância de a Redecentro ocupar-se com processos formativos que sejam capazes de mudar formas de pensamentos de seus(as) pesquisadores(as). Lembremos que o grupo aglutina vários tipos de pensamento, os quais buscam manter conceitos e posturas frente a um mesmo objeto de estudo. Por certo, se esse aspecto não for considerado e balizado ao longo dos trabalhos da Rede, o grupo será destoante e pode até chegar a decisões diferentes e conflituosas.

Portanto, assumimos como desafio-chave da investigação colaborativa, formas de motivação e desenvolvimento de um pensamento que autorregule a consciência metacognitiva, e a consequente vigilância epistemológica de alto nível. Conforme recorte aqui proposto, assumimos que a adequada expressão científica do pensamento crítico e colaborativo, filia-se a metacognição e a vigilância epistemológica (PÉREZ et al, 2021).

Dando centralidade à clareza do conceito, a metacognição relaciona-se ao como pensar sobre o pensar e, diante disso, sustenta duas dimensões: "conhecimento metacognitivo e regulação metacognitiva" (PÉREZ, GÓMEZ GALINDO; GONZÁLEZ GALLI, 2021, p. 30). Ambas se ligam a importância da dinamicidade e poder de autorreflexão (SOUZA, 2012). 
Souza (2012, p.16) complementa a ideia destacando que a "capacidade de pensar sobre nossos próprios pensamentos”, em suas dimensões social, intelectual, técnica, interna e espiritual, liga-se, epistemologicamente, a atitude metacognitiva. Ela enfatiza a negação do pensamento reducionista (linear positivista) encaminhando os sujeitos à identificação do saber e seu sabor, além de favorecer a discussão ética em todo conhecimento (BRUNER 1996). Do que se entende que negar o pensamento reducionista para apoiar a postura ética na pesquisa, acabam sendo dimensões promovidas pela metacognição.

Nesse sentido, a iniciativa formativa que se ocupa de seu desenvolvimento, também ajuda a fundamentar sua importância ao relacionarse dignamente consigo mesmo e com o outro. Isso envolve preparar os(as) pesquisadores(as), em sua complexidade, para o pensamento emancipatório, de libertação, autônomo, criativo e inovador, aspectos caros à investigação colaborativa. Encontra-se implícito nesta formulação, portanto, que o conhecimento metacognitivo é aquele que os sujeitos possuem por conta própria, mas pode ser incentivado, e ainda lhe pertence o cultivo da dimensão utópica, como definiu Freire (1998), compreendida como aprendizagem de se construir o que se projeta, no sentido da autonomia e do bem comum.

A vigilância epistemológica, por sua vez, que também é metacognitiva em essência, relaciona-se teoricamente à capacidade de superar os obstáculos epistemológicos, pois implica desenvolver uma capacidade de regular as dificuldades encontradas durante a construção ou uso do modelo científico de interesse, além de envolver e monitorar a linha ideológica política assumida.

Nessa lógica, a vigilância epistemológica dá as diretrizes para a construção teórica de um adequado problema de pesquisa, questões pertinentes, objetivos em conformidade. Ela ainda articula o aspecto conceitual sobre o método apresentado e assumido nos estudos, sua formalização e explicitação da intencionalidade do método, como a lógica da condução da construção do conhecimento. Ajuda a manter a constante preocupação com o posicionamento teórico frente a construção metodológica, bem como na adequada explicitação de conceitos, como o ideário pedagógico, 
que deve deixar claro suas filiações. Resumidamente, cabe a vigilância epistemológica sustentar a tradição teórica que os(as) pesquisadores(as) aderem, além de explicito posicionamento político crítico, o que revela a preocupação com o rigor científico e a relevância de seus estudos (MAGALHÃES; SOUZA, 2018; 2019; MAGALHÃES, 2019a; 2019b).

E ainda, seria a partir da vigilância epistemológica que se torna possível a expressão de uma forte crítica, baseada na formação e condições sociais que condicionam a prática intelectual. Quando o(a) pesquisador(a) expressa sua vocação, e o como ela traz à tona a reflexão sobre a sua própria prática da pesquisa, é capaz de mostrar sua força para gerar mudanças no contexto social. Assim, a investigação colaborativa exige um caminho que passa por mudanças teórico-conceituais, as quais se ocupam de sanar déficits formativos entre os(as) pesquisadores(as). Essa é uma realidae na Redecentro, quando às possibilidades de expandir a metacognição estão presentes, gradativamente, consolida-se o pensamento emancipado, e por meio da vigililância epistemológica que este promove, amplia-se a conscientização.

A metodologia de consolidação da investigação colaborativa aqui adotada representa o esforço da Redecentro de reconhecer suas ações como complemento, não definitivo na mudança conceitual dos(as) pesquisadores(as). Por isso, desde este entendimento, a Rede ocupa-se em orientar e melhorar a didática formativa de seus(as) pesquisadores(as), o que tem ajudado a sanar deficiências relacionadas a formação teórica e filosófica, ao fortalecer meios que permitam uma nova forma de pensar a pesquisa educacional.

O processo formativo de princípios orientadores da metacognição e da vigilância epistemologica: teórico, epistemológico, metodológico, axiológico, gnosiológico, político

Toda investigação colaborativa na e em rede, como aquela desenvolvida na e pela Redecentro, exige domínio de um referencial teórico, filosófico e metodológico. Esse é um ponto comum entre seus membros. 
Parte-se do pressuposto que os(as) pesquisadores(as) possuem esse domínio ou precisam do apoio do grupo para que haja o domínio dos aportes teóricos e metodológicos que sustentarão a pesquisa.

$\mathrm{Na}$ perspectiva da experiência formativa da Redecentro, busca-se dar apoio a construção dos princípios - estruturantes - teórico, epistemológico, gnosiológico, ontológico, metodológico, político e ideológico, e relacional entendendo que podem direcionar as reflexões e as ações do grupo que compõem a Rede, bem como a convivência, o respeito e a ética dos(as) pesquisadores(as), conforme propõem Saul; Giovedi, (2016).

Dessa forma, a entrada e permanência na Rede exige participação nos seus Grupos de Estudos e Pesquisas, cujo material formativo varia conforme o grupo de pesquisadores: se são iniciantes ou não. Cada grupo de estudos e pesquisas é coordenado por um membro doutor, de cada instituição, escolhido pelo grupo, em alternância. Nossa preocupação em manter os grupos de estudos tem sido central, primeiro pela necessidade de nivelar o entendimento de conceitos centrais às pesquisas. Segundo, porque dão suporte aos debates nos momentos de Reuniões Técnicas de coordenação, nas Reuniões de estudantes de pós-graduação, bolsistas, e monitores, nas reuniões destinadas as discussões sobre as pesquisas - coleta, sistematização, discussão e análise de dados, e construção de material de divulgação de resultados - artigos, dissertações e teses.

Cada um dos momentos citados consolida, gradativamente, o que aqui definimos como princípios, e isso inclui desde os(as) doutores(as) orientadores(as) até os(as) estudantes de graduação. Consolida-se, assim, a ambiência das ações de pesquisas.

No que se refere ao princípio teórico e epistemológico, relaciona-se diretamente aos processos metacognitivos e de vigilância crítica da produção do conhecimento, pois lhe pertence o rigor teórico na definição de concepções, ajuda a "descortinar" e perseguir a dimensão "radical e radicante" de cada conceito, o que pressupõe pensar a concretude de sua historicidade (SAVIANI, 2017). Nessa perspectiva, quando os(as) 
pesquisadores(as) se propõem investigar, precisam ter em mente que a sua lógica teórica interfere na forma como vêm e pensam os fenômenos, e que seu pensar é sempre respaldado em aportes teóricos, os quais influenciarão nas etapas da pesquisa.

O princípio teórico e epistemológico respalda o trabalho intelectual, a produção de ideias, conceitos e representações, que se relacionam com as possibilidades de compreender e transformar a realidade. Sem esse princípio, tem-se apenas um exercício intelectual, uma reflexão da ação pela ação que rompe a dinâmica dialética entre teoria e prática na pesquisa (VÁZQUEZ, 1968; SOUZA; MAGALHÃES, 2019).

Ressalte-se ainda que esse princípio é necessário para a manutenção do rigor e da vigilância epistemológica da pesquisa, mas ele se dá no pensamento, o que exige a dialética na dinâmica da construção de significados, ou como afirma a proposta marxista, na elaboração do concreto pensado.

Magalhães e Souza (2019) sustentam que o princípio teórico pode pautar-se em duas epistemologias que se confrontam: a epistemologia da prática e a epistemologia da práxis. No campo da epistemologia da prática, a perspectiva teórica é o positivismo (MAGALHÃES; SOUZA, 2018; 2019; MAGALHÃES; MOURA, 2020). Representa uma base epistemológica que sustenta o posicionamento político-ideológico hegemônico, compreendendo as relações sociais como dadas e a-históricas, portanto, não há perspectivas de transformação social, somente manutenção das relações sociais.

A epistemologia da prática, portanto, centra-se na ideia de que a produção do conhecimento pode ser reduzida ao conhecimento prático, de caráter instrumental e pragmático; submete a produção a dicotomia teoria e prática. Tello (2013) afirmou que o conhecimento construído a partir dessa epistemologia não é uma construção social, mas refere-se à apropriação individual da realidade objetiva, parcial, e limita-se à percepção imediata, organizando-se como conhecimento pragmático. O critério de verdade do conhecimento para essa base epistemológica é a sua utilidade prática para a manutenção ou aperfeiçoamento da ordem estabelecida. 
Conforme afirmam Souza e Magalhães (2019), a epistemologia da prática ampara concep̧̧ões acadêmicas, pedagógicas e políticas, sustentadas na individualidade e numa postura alienada, assegurando uma base gnosiológica auxiliar no agravamento das condições sociais de desigualdade, geradas pelo capitalismo, o que impede a realização da humanização, da democracia e da cidadania plena. Scalcon (2008), afirma que a visão da epistemologia da prática tem como fundamento um paradigma que entende o conhecimento como individual, circunstancial, parcial, reduzido ao contingente e a prática imediata.

A epistemologia da práxis, em contrapartida, funda-se na relação dialética entre teoria e prática, reafirmando sua indissociabilidade, o que consolida a práxis no contexto da pesquisa. Para essa base epistemológica, o conhecimento tem sentido coletivo e social, caracterizado como emancipador e humanizador. Esse mesmo sentido pode ser identificado a partir do posicionamento político ideológico contra hegemônico dos(as) pesquisadores(as), e que, por isso, assumem a necessidade de promover perspectivas de transformação social, por meio do confronto com a prática hegemônica.

A epistemologia da práxis afirma uma racionalidade cuja produção de conhecimento, sobre qualquer fenômeno, exige destacar sua historicidade, materialidade e contexto. Apresentamos uma concepção de educação, a partir dessa base epistemológica para exemplificar. Consideramos, por isso, que a educação é:

[...] uma forma de intervenção na vida coletiva, no sentido de manutenção de uma determinada realidade ou de sua superação [...] a educação deve servir a um projeto de construção de uma sociedade mais livre, humana, justa e democrática (SAUL; GIOVEDI, 2016, p. 214).

Podemos ponderar, ainda, segundo Freire (1998, p.98, grifos do autor), que a educação é uma forma de intervenção no mundo, que implica o esforço de "reprodução da ideologia dominante quanto o seu 
desmascaramento", num movimento dialético e, ao mesmo tempo, contraditório. Por isso mesmo, não é e jamais será neutra.

Essa concepção de educação, que é referenda numa abordagem crítica e política, deixa explícito que ela deve "contribuir com os processos de luta pela superação das diversas formas de exploração e dominação vigentes”. Assumir essa concepção de educação a implica, na pesquisa, a "luta política pela transformação da sociedade em que vivemos" (SAUL; GIOVEDI, 2016, p. 214).

Para o grupo que compõe a Redecentro, o estudo dos teóricos críticos é exigido e consolida o princípio dessa epistemologia. Afinal, ela não permite a neutralidade, pois a pesquisa, assim como a educação, como já o dissemos, é ação política que depende do(a) professor(a) pesquisador(a) para a materialização e a reinvenção de proposições e práticas, na construção de uma pesquisa problematizadora, emancipadora, libertadora.

O amplo repertório de conceitos estudados, sempre a partir de uma base crítica e dialética, ampliam a apropriação que os(as) pesquisadores(as) fazem dos referenciais estudados e o como os levam ao campo da pesquisa. Isso nos parece fundamental para ampliar níveis de consciência dos(as) membros da Redecentro, para que eles(as) possam desenvolver uma postura questionadora da realidade e uma atitude de pesquisa mobilizada e organizada nos mesmos termos. Por certo, essa base epistemológica, ao dar suporte teórico às pesquisas, exige um processo metacognitivo e mantém a vigilância epistemológica para que assumam sua qualidade socialmente relevante.

O próximo princípio é o gnosiológico. A definição de gnosiologia aqui proposta vem do termo grego gnosis, cujo significado diz respeito à teoria do conhecimento. Tem objetivo centrado no estudo da possibilidade, legitimidade, valor e limites do conhecimento humano. Portanto, a gnosiologia se relaciona à ideologia (MAGALHÃES; ARAUJO; ARGÜELLO, 2020c), à política, aos princípios, valores e crenças, implícitos no conhecimento, mas se diferencia da epistemologia que tem como objeto o conhecimento científico, como esclareceu Saviani (1991). 
Segundo a abordagem teórica que nos sustenta, o princípio da gnosiologia faz parte de uma pesquisa enquanto a práxis. Práxis é aqui pensada como categoria fundante não só do posicionamento epistemológico, como do gnosiológico, pois ajuda a conceber a pesquisa como atividade social humana, fundamental para o entendimento dos processos de elaboração de conhecimentos e da omnilateralidade da formação humana (VÁZQUEZ, 1968).

Assim como o princípio epistemológico, a gnosiologia pode ser fundamentada na gnosiologia da prática e da práxis. Quando se funda na gnosiologia da prática destacam-se valores que se ligam ao imediatismo e aos limites do realismo empírico. Seus valores passam a fortalecer princípios individualistas, reforçando um pensamento convergente à dominação/submissão, o que agrava processos de alienação e que, politicamente, expressam apoio e adesão à lógica neoliberal. Nesta proposta adere-se a uma ética descartável, caracterizada por valores mutáveis e momentâneos. No que diz respeito à produção de conhecimentos, ela tornase superficial, fragmentada, discriminatória, produto que pode ser comercializado. E é contra essa lógica que Freire (1998) nos propõe a rebeldia e a luta por transformação.

Em contrapartida, ao considerar a dimensão gnosiológica da práxis, as contradições conferem a necessidade de projetos históricos que enunciem o tipo de sociedade que se quer construir e com quais meios, finalidades e valores, pois os projetos históricos estão ligados às concepções de homem [e mulher] e de sociedade que também condicionam a produção do conhecimento.

Por certo, o princípio gnosiológico não só influencia como participa diretamente nos processos de metacognição e vigilância epistemológica e, dependendo do posicionamento gnosiológico assumido, teremos condutas que expressam a ideologia e as escolhas políticas dos(as) pesquisadores(as). Embora já entendamos que essas ainda podem ser, infelizmente, hegemônicas ou, ao contrário, emancipadoras e contra hegemônicas (SOUZA; MAGALHÃES, 2019). 
Outro princípio orientador da pesquisa colaborativa e em rede é o ontológico, que se relaciona ao nível do ser (ontológico), considerado na interlocução do pensar (gnosiológico) e o do conhecimento (epistemológico). A ontologia está relacionada à ideia da totalidade do ser, a sua materialidade, ao como os homens produzem sua existência, como se formam como seres sociais, como se produz coletivamente a humanidade (DUARTE N., 2004).

Da mesma forma, dando sequência ao teorizado, este princípio também precisa ser pensado a partir de uma ontologia da práxis e a ontologia da prática (MAGALHÃES; SOUZA, 2018; 2019; MAGALHÃES, 2019a; 2019b; MAGALHÃES; FORTUNATO; MENA, 2020). Na perspectiva da ontologia da práxis ou materialista dialética, o conhecimento é capaz de promover uma atividade transformadora, constituidora e constituinte do ser humano, histórico, e que no seu processo de conscientização almeja por transformações sociais, políticas, pessoais. Portanto, o homem e a mulher são sujeitos históricos que questionam, por exemplo, sobre a sua adaptação, ou resistência propositiva ${ }^{5}$ à lógica neoliberal do homem [e da mulher] individualista, alienado(a), fragmentado(a).

Já a partir dos fundamentos da ontologia da prática, que se contrapõem à ideia da possibilidade da práxis, o conhecimento é fragmentado, idealizado, pragmático, descontextualizado, não se sustenta pela materialidade, historicidade ou, na possibilidade de transformação política, social e cultural. Portanto, não contribui para a qualidade social do conhecimento.

A Redecentro investe no entendimento desses princípios para que os(as) pesquisadores(as) que a integram sejam capazes de ir contra as pressões neoliberais, para que se evite a continuidade de professores(as) pesquisadores(as) alinhados à ontologia da prática, a qual, como afirma Ball (2002, p. 5), impõe determinada performatividade aos(às) professores(as)

\footnotetext{
${ }^{5}$ Ao tratarmos de resistência propositiva, a vinculamos à dimensão "popular". A formulação da expressão resistência propositiva popular incorpora, conforme Novais e Souza (2019) a compreensão e o reconhecimento de que a sua construção exige redes abertas e democráticas de produção e divulgação de conhecimentos, saberes e experiências complexos, vinculados aos diferentes lugares, sujeitos ou grupos sociais, e processos de superação de qualquer obstáculo à emancipação humana. Dessa forma, ao identificar e analisar movimentos de resistência em contextos escolares, são evidenciados pautas, proposições, dinâmicas e valores que podem permitir nomeá-los como movimentos de resistência propositiva popular.
} 
pesquisadores(as), implantada para estabelecer "novas identidades, novas formas de interação e novos valores". Afirmamos que a racionalidade neoliberal traz consequências drásticas ao princípio ontológico, pois aumenta a individualização e um esmaecer de solidariedades.

No que se refere aos processos de metacognição e vigilância epistemológica, seguimos afirmando que princípio ontológico acata o princípio dialético da contradição, e pode ajudar a demarcar novos caminhos de resistência propositiva, conforme propõem Novais e Souza (2019).

O princípio metodológico, por sua vez, ancora-se numa concepção de pesquisa que se inspira nos princípios do método materialismo históricodialético, bem como, pela especificidade de alguns objetos de estudo, o método fenomenológico, Em qualquer aporte metódico, Expressam-se características que pressupõem a aprendizagem individual e coletiva e, embora não exista a certeza de que "todos os participantes tenham a mesma agenda ou o mesmo poder institucional ou de saber", conforme expressou MAGALHÃES; SOUZA (2018; 2019) esse princípio exige sempre a capacidade de negociação das representações e valores de cada membro do grupo. Nesse ponto, se instaura a essência do trabalho coletivo e colaborativo, conforme abordagem marxista e freiriana.

A proposição de Frigotto (1996) é por nós assumida, ao reforçar que o princípio metodológico deve promover a pesquisa como atividade humana de produção, de transformação, que se desenvolve a partir de uma riqueza de vivências dos sujeitos (conteúdo) e nas relações com o grupo (forma), gerando um campo contextual coletivo de produção da experiência histórica e cultural, como propõe Freire (1998). Pensamos ainda que o princípio metodológico, enquanto dimensão da investigação colaborativa em rede, exige que seus membros partilhem temas, objetos de estudos, abordagens representativas da perspectiva dialética, tipos de pesquisas que respondam a necessidade da explicitação da historicidade e aspectos condicionantes do objeto de estudo, objetivos - geral e específicos, partilhados, ampla teorização e sistematização do 
conhecimento sobre o objeto de estudo, coerência na construção de perguntas exploratórias comuns, que, por já estarem amplamente respaldada nos princípios teóricos e epistemológicos, passam a consolidar o caminho da pesquisa. Portanto, esse princípio exige uma construção coletiva desde o início do desenho metodológico: instrumentos e sua validação na coleta de dados, análises, interpretações, inclusive na publicização coletiva e intervenções a partir dos resultados obtidos.

Esse princípio, que se soma aos outros já discutidos, inspira e melhora a capacidade metacognitiva e a vigilância epistemológica da pesquisa, tornando-a práxis humanizadora e emancipadora. Essa ideia está presente no nosso movimento de pensamento sobre a investigação colaborativa, por isso reforçamos o espaço da pesquisa como possibilidade de re-existir, de reinventar e criar contextos abertos para que todos os membros falem, questionem, relatem divergências e convergências, o que parece bastante pertinente no fortalecimento do grupo.

Por certo, o processo formativo que exige a investigação colaborativa e em rede, chega ao nascedouro e fortalecimento do posicionamento político $e$ ideológico. Esse deve ser comprometido com os processos de luta pela superação das diversas formas de exploração e dominação vigentes. Evocamos Freire (1998) que confirmou que a vocação política da educação se volta à especificidade do humano. Ao se transportar essa ideia para a investigação colaborativa, expressamos a importância da politicidade, tornando-a inerente à natureza da pesquisa e da produção do conhecimento. Ambos devem contribuir com a luta política pela transformação da sociedade atual.

Se é impossível a neutralidade da educação, da mesma forma o é no que se refere a produção de conhecimento. Conforme esclareceu Freire (1998, p. 110), embora estivesse falando sobre a educação, ele afirma que ela "não vira política por causa da decisão deste ou daquele educador. Ela é política”. O mesmo ocorre com a investigação colaborativa em rede, ela não vira política por causa da decisão deste ou daquele pesquisador, ela é 
política, porque representa grupos, porque carrega concepções e valores que se reforçam o posicionamento político dos(as) pesquisadores(as).

O posicionamento político sendo crítico e contra hegemônico, pode destacar um enfoque especial na consolidação de processos metacognitivos e de vigilância epistemológica, sobretudo dirigindo-as a resistência propositiva à ação neoliberal.

Outro princípio importante é o relacional. A investigação colaborativa pode gerar a oportunidade de se criar e se consolidar vários benefícios de uma associação de pessoas. Por certo, darão as estratégias emancipadoras "pelo poder político conquistado pela pesquisa científica e pela legitimidade recebida da comunidade acadêmica” (FRANCO; MOROSINI, 2001, p. 20).

Nossaexperiência permite-nos perceber que há a necessidade do entrelaçamento da razão e do desejo na construção de respostas capazes de ajudar o grupo. Isso envolve assumir e enfrentar os desafios, sempre na busca de resultados gratificantes para todos(as). Nesse sentido, o grupo faz questão de criar e consolidar o que entende como sendo benefícios dessa associação, na manutenção de aspectos de resistência propositiva (NOVAIS; SOUZA, 2019) e emancipação socioeducativa (MAGALHÃES; FORTUNATO; MENA, 2020; MAGALHÃES; ARAUJO; ARGÜELLO, 2020c).

Dentre os vários aspectos que se articulam nesse fazer colaborativo, o princípio relacional dá centralidade ao diálogo comunicativo-crítico, expressivo, tolerante e verdadeiro.

O grupo de pesquisadores(as) aprofunda o processo de ser mais, estabelecendo uma trajetória de fazer pesquisa em relação ao indispensável diálogo, como método fundamental de trabalho, ao desenvolvimento da tolerância para ouvir e respeitar os(as) interlocutores(as), aceitar e ou confrontar posicionamentos diversos, desenvolver pensamento crítico e humildade intelectual, entre outras categorias freirianas que se apresentam importantes na trama do fazer colaborativo proposto por Freire (1997). 
Como estratégias conduzidas e pensadas a partir desse princípio, ainda se destacam os seminários promovidos pelo grupo, os quais ganharam espaço privilegiado, constituindo-se em mecanismo de articulação entre os(as) pesquisadores(as), de modo a atender as necessidades de planejamento, coleta e organização de dados e discussão dos resultados. São pilares estruturantes que implicam, necessariamente, a constante revisão do processo relacional.

Apoiados em Gasparotto e Menegassi (2016) destacamos alguns aspectos pertinente da investigação colaborativa que passa pelo princípio relacional:

Negociação e interação: no processo de estudo teóricometodológico e de construção de conhecimentos, preza-se pela discussão de valores, conceitos e ideias, fazendo com que o trabalho colabore significativamente para ambas as partes (...); Responsabilidade e engajamento: a responsabilidade do pesquisador está em ser o condutor de todo o processo. Mesmo em coparticipação, é dele o dever de certificar-se de que as ações estejam sendo sempre negociadas, de garantir um espaço favorável à crítica, aos relatos, à reformulação (...); Coparticipação e autonomia: a elaboração conjunta dos objetivos, das fases do processo de colaboração, das atividades a serem desenvolvidas em sala são necessárias para a conexão teoria e prática, considerando o encontro de experiências e conhecimentos que pode ser muito positivo (...); Conexão teoria + prática + sujeito + contexto: ao adquirir novos conhecimentos, não se deve esperar que o professor faça uma transposição direta para a sua prática. As novas informações são, na verdade, incorporadas, somadas a conhecimentos e experiências anteriores. Isso não pode ser desconsiderado (...); Sessões reflexivas: os encontros entre pesquisador e docente podem acontecer durante todo o trabalho de colaboração, é fundamental que isso ocorra para que haja negociação e interação. Esses encontros podem ser para estudo teórico-metodológico, elaboração conjunta de ações ou atividades, discussão sobre o andamento das atividades em desenvolvimentos, avaliação, reavaliação, reformulação de objetivos ou de atividades (GASPAROTTO; MENEGASSI, 2016, p. 954-955. Grifos nossos).

Como sistematizaram Gasparotto e Menegassi (2016), o princípio relacional também agrega postura ética, motivação, criatividade, respeito, afetividade, o que acaba favorecendo a metacognição, o 
autoconhecimento, a humanização e a emancipação dos(as) envolvidos(as) em torno de um objetivo comum.

Do que se entende que o agrupamento fortalece ainda outros aspectos, relacionamentos interpessoais entre os(as) membros(as) da equipe, que, particularmente no nosso caso, iniciada em 2004, sinalizam a valorização das relações estabelecidas como importante característica da investigação colaborativa na e em Rede. Também se destaca a presença de confiança. Como pontua Hargreaves (1998), ela auxilia no estabelecimento de um clima de respeito e cuidado, que se manifesta no pessoal e no profissional.

A confiança é manifestada quando percebemos que os(as) participantes(as) do grupo se sentem à vontade em questionar abertamente as ideias, valores e ações uns dos outros, respeitando-os e sabendo, igualmente, que o seu trabalho e os seus valores são respeitados. A confiança estabelecida está, consequentemente, associada à disponibilidade para ouvir com atenção os outros, na valorização das contribuições, no sentimento de pertença ao grupo, o que indica abertura ao outro, conforme preconiza Freire (1998). Sem confiança entre os(as) participantes e sem confiança em si próprios, não haveria trabalho colaborativo em e na Rede.

A colaboração, outro aspecto importante, pode desenvolver-se entre pares, entre professores(as) pesquisadores(as), que trabalham nos cargos de coordenadores(as) de cada instituição e pode, da mesma forma, ter lugar entre professors(as) e alunos(as), entre alunos(as) e alunos(as), trazendo maior entendimento dos quadros de referência e estilos de trabalho dos(as) membros, ou mesmo no seio de cada equipe que integram a Rede.

Ainda há a expressão emocional. Estudos confirmam que ela tem um papel essencial na capacidade de perceber ativamente os sentimentos e necessidades dos outros, e por poder motivar comportamentos de ajuda (NEWCOMBE; ASHKANASY, 2002; MAYER, SALOVEY, 1997), altruísmo (ORGAN, 1988), auto-aprendizagem e uma aprendizagem acerca das 
relações humanas (OLSON,1977), e outros tipos de assistência interpessoal. A capacidade de compreender os sentimentos dos outros e de re-experienciálos, como se fossem nossos, é uma competência que parece ser importante para a manutenção de relacionamentos sociais construtivos (MAYER, SALOVEY, 1997). Por meio da expressão emocional, o grupo é capaz de comunicar emoções, o que permite a troca efetiva de informações sobre suas necessidades e outras informações emocionais, facilitando o alcance das metas do trabalho colaborativo.

\section{À guisa de conclusão}

A convivência de professores(as)-pesquisadores(as) em ações coletivas mostra o como e o quanto podem ficar envolvidos(as) na busca de entendimento e respostas de vários problemas, que se apresentam ao grupo, no movimento das pesquisas. Essa convivência aumenta nossa certeza sobre a complexidade que caracteriza a investigação colaborativa e em rede, quando em grupo, os(as) pesquisadores(as) dialogam, debatem, questionam, desconstroem e reconstroem caminhos e verdades, gerando um movimento pautado pela singularidade e complexidade, que se revelam a partir do e no trabalho da pesquisa.

Assim, o coletivo suscita a dialogia do discurso, como possibilidade para o exercício da tolerância, do respeito, da partilha e aceitação necessária na busca do pensamento crítico-reflexivo, o que configura caminhos inevitáveis para a superação do individualismo, da desumanização e da alienação.

A importância da investigação colaborativa e em rede se destaca por suas exigências imediatamente coletivas: capacitar no que se refere aos princípios teórico, epistemológico, gnosiológico, ontológico, metodológico, político e ideológico, e relacional, que influem nas subjetividades, linguagens, saberes, conhecimentos, relações profissionais, mas também, e sobretudo, na capacidade metacognitiva e na vigilância epistemológica de cada pesquisador(a) no próprio processo da pesquisa. 
Esses aspectos estão presentes na organização da Redecentro. As especificidades da experiência a coloca como experiência viva, solidária, que impõe a necessidade tomá-la como objeto de metacognição, e relatá-la como uma forma de melhoria de nossa própria práxis, como pesquisadores(as) em rede.

A investigação colaborativa é enraizada em pressupostos inclusivos e provoca a co-construção e a tomada de consciência dos sujeitos, o que permite a retomada de experiências anteriores dos sujeitos que, em interação e por prescindir de atividades coordenadas e sincronizadas, oportuniza a inclusão, a geração de oportunidade de partilha e reflexão, podendo ser assumida como dimensão do trabalho docente coletivo. Nossa experiência revela que a investigação colaborativa e em Rede tem propiciado a construção de um conhecimento não-linear, não-sequencial, alicerçado em uma abordagem que permite mudanças na identidade docente, por meio da consolidação das metodologias assumidas pela Redecentro.

O grupo continua empreendendo esforços para dar continuidade aos processos colaborativos. Apresentam dinâmicas que também são facilitadoras das redes acadêmicas do conhecimento. As redes acadêmicas virtuais, por exemplo, já se constituem como uma referência convencionada e fundamental, atualmente.

Nossa experiência elucida que a amplitude do trabalho exige a colaboração como força de impulsão da qualidade ao que é desenvolvido, favorecendo o trabalho docente coletivo. A partir de certo equilíbrio relacional, cuja regra básica é o apreender colaborando, se inscreve um sistema de valores associados a autonomia, a reflexão, a crítica, a auto-crítica, à humanização, à emancipação, ao empenhamento ativo. Nessa ordem de pensamento, não há como negar que as redes acadêmicas propiciam as redes de conhecimento, capazes de promover mudanças na produção do conhecimento, no desenvolvimento profissional do(a) professor(a)-pesquisador(a), bem como na sua posterior práxis pedagógica.

Podemos concluir que o trabalho colaborativo em rede e, no nosso caso, na Redecentro, numa perspectiva contra hegemônica, permite a consolidação de um espaço aberto e sensível à socialização de dúvidas e 
experiências, no qual o sentido colaborativo-crítico nos ajuda a realizar a investigação com mais segurança, autonomia, sem nos descuidarmos das reflexões e dos embates vividos durante o percurso da pesquisa, o que o consolida como uma importante experiência formativa e coletiva.

\section{Referências}

ALVES. M. M. F. Desenvolvimento profissional docente em ambientes colaborativos de aprendizagem a distância: estudo de caso no âmbito da formação contínua. 2007. 362 f. Tese. (Doutorado em Educação). Instituto de Estudos da Criança.

Universidade do Minho. Portugal, 2007.

BALL, S. J. Reformar escolas/reformar professores e os terrores da performatividade. Revista Portuguesa de Educação, vol. 15, núm. 2, pp. 3-23 Universidade do Minho Braga, Portugal, 2002.

BRUNER, J. L'éducation, entrée dans la culture. Les Problèmes de l'école à lalumière de la psychologie culturelle. Paris, Retz. 1996.

DUARTE, N. Formação do indivíduo, consciência e alienação: o ser humano na psicología de A. N. LEONTIEV. Caderno Cedes, Campinas, v. 24, n. 62, p. 4463, abril, 2004.

FRANCO, M. E. Del Pai. MOROSINI, M. C. (Orgs.). Redes acadêmicas e produção do conhecimento em educação superior. Brasília, INEP, 2001.

FREIRE, P. Criando métodos de pesquisa alternativa: aprendendo a fazê-la melhor através da ação. In. BRANDÃO, Carlos Rodrigues. Pesquisa participante. São Paulo: Brasiliense, 1971.

FREIRE, P. Conscientização e alfabetização: uma nova visão do processo. In: FREIRE, P. Pedagogia do Oprimido. Rio de Janeiro: Paz e Terra, 1997.

FREIRE, P. Pedagogia da Autonomia: saberes necessários à prática educativa. $31^{\mathrm{a}}$ ed. São Paulo: Paz e Terra, 1998.

FREIRE, P. Educação e mudança. 34.ed. Rio de Janeiro: Paz e Terra, 2011a.

FREIRE, P. Educação como prática da liberdade. 34.ed. Rio de Janeiro: Paz e Terra, 2011b.

FRIGOTTO, G. A formação e profissionalização do educador: novos desafios. In: GENTILLI, P.; SILVA, T. T. da (Orgs). Escola S.A. Brasília, CNTE, 1996.

GASPAROTTO, D. M.; MENEGASSI, R. J. Aspectos da pesquisa colaborativa na formação docente. Perspectiva, Florianópolis, v. 34, n. 3, p. 948-973, set./ago. 2016. 
HARGREAVES, A. Os professores em Tempos de Mudança. Amadora: Editora Mcgraw-Hill de Portugal, L., 1989.

HOLLIDAY, Oscar Jara. Para sistematizar experiências. Tradução de Maria Viviana. V. Resende. 2. ed., revista. - Brasília: MMA, 2006.

MAGALHÃES, S. M. O.; SOUZA, R. C. C. R. Epistemologia da práxis e a produção do conhecimento. R. Educ. Públ. Cuiabá, v. 27, n. 64, p. 17-40, jan./abr. 2018.

MAGALHÃES, S. M. O. Epistemologia da práxis: enfoque emancipatório e contra hegemônico na produção acadêmica. Revista Intersaberes, vol. 13, n. 30, 2019a.

MAGALHÃES, S. M. O. Violência política e ideológica contra os professores: a pedagogia do oprimido como medida de intervenção e transformação. International Journal of Latest Research in Humanities and Social Science (IJLRHSS). Volume 02. pp. 01-05- Issue 02, 2019b.

MAGALHÃES, S. M. O.; SOUZA, R. C. C. R. (Orgs.). Epistemologia da Práxis e Epistemologia da Práxis: Repercussões na Produção de Conhecimentos sobre Professores. Campinas, SP: Mercado das Letras, 2019.

MAGALHÃES, S. M. O.; FORTUNATO, I.; MENA, J. La universidad como resistencia: en busca de una epistemología de la práxis. Rev. HISTEDBR On-line. Campinas, SP v.20 1-14 e 020001, 2020.

MAGAlHÃES, S. M. O.; ARAUJO, S. M.; ARGÜELLO, S. B. Agudización ultra neoliberal, educación Y formación docente em Brasil Y Argentina. Revista Interação, Goiânia, v. 45, n. 1, p. 49-80, jan/abr, 2020.

MARX, K.; ENGELS, F. A Ideologia Alemã (I -Feuerbach), Trad. José Carlos Bruni e Marco Aurélio Nogueira. 5. ed. São Paulo: Editora Hucitec, [1846] 1986.

MAYER, J. D.; SALOVEY, P. What is Emotional Intelligence? In P. Salovey and D. J. Sluyter (Ed.) Emotional Development and Emotional Intelligence: Educational Implications, pp. 3-25. NY: Basic Books. Moorman e Blakely, 1997.

MOROSINI, M. C. Pedagogia universitária e campo do conhecimento: RIESRede sulbrasileira de Investigadores da Educação. In: MOROSINI, Marília Costa (Org.). Enciclopédia de pedagogia universitária. Porto Alegre, FAPERGS/ RIES, p. 219-228, 2003.

NEWCOMBE, M. J., ASHKANASY, N. M. The role of affect and affective congruence in perceptions of leaders: an experimental study. The Leadership Quarterly, 13 (5), 2002.

NOVAIS, G. S.; SOUZA, T. Z. Marco de Referência de Educação Popular para as Políticas Públicas Educacionais. Relatório. Uberlândia, 2019, 18p. 
OLSON, M. Collaboration: An epistemological shift. In H. Christiansen, L. Goulet, C. Krentz; M. Macers (Orgs.), Recreating relationships: Collaboration and educational reform (pp. 13-25). New York, NY: State University of New York Press, 1977.

ORGAN, D. W. Organizational citizenship behavior: The good soldier syndrome.Lexington, MA: Lexington Books, 1988.

PÉREZ, G., GÓMEZ GALINDO, A. A. Y GONZÁLEZ GALLI, L. La regulación de los obstáculos epistemológicos en el aprendizaje de la evolución. Enseñanza de las Ciencias, 39(1), 27-44, 2021.

SAUL, A. M. Paulo Freire na atualidade: legado e reinvenção-uma pesquisa a várias mãos. Revista e-Curriculum [en linea], 14 (Enero-Marzo), 2016.

SAUL. A. M.; GIOVEDI, V. M. Pedagogia de Paulo Freire como referência teóricometodológica para pesquisar e desenvolver a formação docente. Revista eCurriculum, São Paulo, v. 14, n. 01, p. 211-233 jan./mar. 2016.

SAVIANI, D. Epistemologias da política educacional: algumas precisões conceituais. Revista de Estudios Teóricos y Epistemológicos en Politica Educativa, v. 2 , n. 1, p. 1-6, 2017.

SAVIANI, D. Escola e Democracia. 25 ed. São Paulo: Cortez: Autores Associados, 1991.

SEVERINO, A. J. Pesquisa educacional: da consistência epistemológica ao compromisso ético. RIAEE Revista Ibero-Americana de Estudos em Educação, Araraquara, v. 14, n. 3, p. 900-916, jul./set., 2019.

SOUZA, R. C. C. R. de. Ribeiro de Novos paradigmas: pontes entre o mal-estar e o bem estar Docente, In: Linhas Críticas, Brasília, DF, n. 36, p. 433-453, maio/ago. 2012.

SOUZA, R. C. C. R de.; MAGALHÃES, S. M. O. Epistemologia da práxis e a produção do conhecimento. Revista de Educação Pública, v. 27, n. 64, p. 17-40, 2017

SOUZA, T. Z. A extensão popular em educação ambiental e seus processos educativos. 2017. 305 f. Tese (Doutorado em Educação) - Universidade Federal de São Carlos, São Carlos, 2017.

VAZQUEZ, A. S. Filosofia da práxis. Rio de Janeiro: Paz e Terra. 1968.

VIGOTSKI, L. S. Formação social da mente. $4^{\mathrm{a}}$ ed. São Paulo, Martins Fontes, 1991.

ZANOLLA, S. R da S. O conceito de mediação em Vigotski e Adorno. Psicologia \& Sociedade, v. 24, n. 1, p. 5-14, 2012. 